\section{RMD Open}

Rheumatic \&

Musculoskeletal Diseases

\title{
In vitro evaluation of disease-modifying antirheumatic drugs against rheumatoid arthritis associated pathogens of the oral microflora
}

\author{
Manuel Kussmann (D , ${ }^{1}$ Markus Obermueller, ${ }^{1}$ Kathrin Spettel, ${ }^{2}$ Stefan Winkler, \\ Daniel Aletaha ${ }^{3}{ }^{3}$
}

To cite: Kussmann M, Obermueller M, Spettel K, et al. In vitro evaluation of diseasemodifying antirheumatic drugs against rheumatoid arthritis associated pathogens of the oral microflora. RMD Open 2021;7:e001737. doi:10.1136/ rmdopen-2021-001737

- Additional supplemental material is published online only. To view, please visit the journal online (http://dx.doi.org/10. 1136/rmdopen-2021-001737).

Received 16 May 2021 Accepted 8 September 2021

Check for updates

(c) Author(s) (or their employer(s)) 2021. Re-use permitted under CC BY-NC. No commercial re-use. See rights and permissions. Published by BMJ.

${ }^{1}$ Department of Internal Medicine I, Division of Infectious Diseases and Tropical Medicine, Medical University of Vienna, Wien, Austria

${ }^{2}$ Department of Laboratory Medicine, Division of Clinical Microbiology, Medical University of Vienna, Wien, Austria ${ }^{3}$ Department of Internal Medicine III, Division of Rheumatology, Medical University of Vienna, Wien, Austria

Correspondence to Professor Daniel Aletaha; daniel.aletaha@meduniwien. ac.at

\section{ABSTRACT}

Objectives In the past, the human microbiome has consistently been associated with rheumatoid arthritis (RA) and disease activity. Here, we investigate the antimicrobial activity of disease-modifying antirheumatic drugs (DMARDs) against typical representatives of the oral microflora that have been associated with RA.

Methods DMARDs were screened for antimicrobial activity against bacteria that are associated with the pathogenesis of the disease and/or frequently isolated from the oral microflora of patients with RA. Screening was done by an agar diffusion assay and minimum inhibitory concentrations (MICs) of antimicrobial active substances were then determined by broth dilution.

Results Aurothiomalate and sulfasalazine demonstrated broad-spectrum antimicrobial activity, but with MICs ranging from 18 to $>280 \mu \mathrm{g} / \mathrm{mL}$ and 150 to $>600 \mu \mathrm{g} /$ $\mathrm{mL}$, respectively, only at supratherapeutic concentrations. Methotrexate showed antimicrobial activity only against Fusobacterium nucleatum and Viridans streptococci. The corresponding MICs were 3.75 to $>30 \mu \mathrm{g} / \mathrm{mL}$ and 0.5-15 $\mu \mathrm{g} / \mathrm{mL}$, respectively, thus at least for streptococci, within the therapeutically achievable range. No other DMARD tested showed antimicrobial activity in the agar diffusion screening assay.

Conclusion Methotrexate, sulfasalazine and aurothiomalate showed antimicrobial activity against a broad spectrum of RA associated pathogens of the oral microflora. While methotrexate showed relevant antimicrobial activity, and to a more limited extent aurothiomalate, sulfasalazine was active only at far supratherapeutic systemic concentrations. Nevertheless, given the highly species-dependent antimicrobial activity and the multiple ways it can affect the human microbiome our results suggest a link between antimicrobially active antirheumatic drugs and their potential effect in the treatment of RA.

\section{INTRODUCTION}

In recent years, there has been an increasing body of literature demonstrating a link between distinct microbial infections, periodontal disease (PD) and the initiation and

\section{Key messages}

What is already known about this subject?

- A growing body of literature indicates a microbia origin for the pathogenesis of rheumatoid arthritis.

What does this study add?

- Disease-modifying antirheumatic drugs (DMARDs) possess a strongly species-dependent antimicrobial activity against organisms of the oral microflora.

- While methotrexate and, to a lesser extent, aurothiomalate showed relevant antimicrobial activity, all other DMARDs tested were active only at far supratherapeutic concentrations.

How might this impact on clinical practice or further developments?

- Future studies linking target site pharmacokinetics, mucosal immune response and oral microflora alterations are needed.

perpetuation of rheumatoid arthritis (RA). ${ }^{1-3}$ Some of the hypothesised pathogenic mechanisms are the generation of neoautoantigens by citrullination of proteins through bacterial enzymes, as well as triggering autoantibody production by molecular mimicry and the expression of bacterial superantigens. ${ }^{2}{ }^{3} \mathrm{It}$ has been shown that Porphyromonas gingivalis, one of the most common causative pathogens of $\mathrm{PD}$, is the only prokaryotic organism with the ability to generate citrullinated autoantigens using its unique peptidylarginine deiminase. This was supported by an experimental arthritis model in mice, which showed that $P$. gingivalis increased levels of citrullinated proteins and autoantibodies, resulting in accelerated progression and aggravated disease severity. ${ }^{4}$ Furthermore, in patients with RA, the levels of anticyclic citrullinated peptide antibodies and rheumatoid factor were shown to correlate with $P$. 
gingivalis antibodies and even direct DNA detection of periodontitis pathogens from serum and synovial fluid was achieved. ${ }^{25}$ In this context, the oral microflora and especially common periodontal pathogens have been extensively studied. In addition, more common infectious agents such as Proteus mirabilis, a frequently isolated urinary tract pathogen, or Staphylococcus aureus, have also been described in the context of RA. ${ }^{23}$

First-line treatment of RA consists of conventional synthetic disease-modifying antirheumatic drugs (csDMARDs) such as methotrexate (MTX) or sulfasalazine (SSZ), both of which have been shown to have antimicrobial activity against various prokaryotes. ${ }^{3}$ In addition, several studies demonstrated the utility of tetracycline antibiotics for treatment of RA, supporting a potential mechanism of action based on antimicrobial activity against disease-initiating and/or diseaseexacerbating pathogens. ${ }^{3}$ Furthermore, although different in aetiology, the ability of bacterial infections to trigger aberrant immune responses is clearly evident also from diseases such as reactive arthritis.

Despite this evidence and the abundance of studies examining the oral and/or gut microbiome and subsequent changes in composition caused by specific antirheumatic drugs, there are few data on the direct antimicrobial activity of DMARDs, particularly against periodontal pathogens. ${ }^{6-14}$ One study conducted a highthroughput drug screening of 835 non-antibiotic agents to evaluate their potential antimicrobial activity against representative bacterial species of the human gut microbiome, but only two DMARDs, namely auranofin and MTX, were included. ${ }^{14}$ Overall, this in vitro study and previous microbiome studies demonstrated highly genusdependent and/or species-dependent antimicrobial activity. Therefore, the potential antimicrobial activity of DMARDs against periodontal pathogens and commensals of the oral microflora cannot be extrapolated from the existing literature.

\section{METHODS}

\section{Bacterial strains}

We selected candidate organisms associated with the pathogenesis of RA or enriched in the oral microbiome of patients with active RA. ${ }^{236915}$ In addition, S. aureus, P. mirabilis and Escherichia coli, which have also been described as potential disease-initiating and/or diseaseexacerbating pathogens, were investigated. All bacteria used in the present study were clinical isolates of the oral microbiome, kindly provided by the Department of Clinical Microbiology of the Medical University of Vienna. In addition following standardised strains from the American Type Culture Collection (ATCC) and the German Collection of Microorganisms and Cell Cultures (DSMZ) were used: Actinomyces naeslundii DSMZ-43013, Capnocytophaga sputigena DSMZ-7273, Eikenella corrodens DSMZ-8340, E.coli ATCC-25922, Fusobacterium nucleatum DSMZ-15643, Parvimonas micra DSMZ-20468, P. gingivalis
DSMZ-20709, Prevotella intermedia DSMZ-20706, P. mirabilis ATCC 14273, S. aureus ATCC-29213 and Streptococcus salivarius ATCC-7073.

\section{DMARDs and controls}

For this study, csDMARDs were selected for which antimicrobial activity was considered likely, based either on the existing literature or their structure: azathioprine, D-penicillamine, sodium-aurothiomalate-hydrate (ATM), SSZ (SSZ; all from Sigma-Aldrich, Austria) and chloroquinediphosphate, hydroxychloroquine-sulfate, leflunomide, MTX, tofacitinib (all from Selleckchem, Germany). Sodium-penicillin-G (Sigma-Aldrich, Vienna, Austria) and sodium-cefuroxime (Fresenius-Kabi, Austria) served as positive controls for the agar diffusion assay.

\section{In vitro susceptibility testing}

Agar diffusion screening assay

Bacterial inocula were prepared by culturing anaerobic bacteria (Actinomyces spp, Capnocytophaga spp, E. corrodens, F. nucleatum, $P$. micra, $P$. gingivalis and $P$. intermedia) on prereduced Brucella agar plates with $5 \%$ horse blood for 72 hours at $36^{\circ} \mathrm{C}-37^{\circ} \mathrm{C}$ in an anaerobic chamber. Streptococci were cultured on Mueller-Hinton fastidious agar plates supplemented with $5 \%$ horse blood for 24 hours at $36^{\circ} \mathrm{C}-37^{\circ} \mathrm{C}$ in a $\mathrm{CO}_{2}$ enriched environment while aerobic bacteria (E. coli, P. mirabilis and S. aureus) were cultured on Mueller-Hinton agar plates for 24 hours at $36^{\circ} \mathrm{C}-$ $37^{\circ} \mathrm{C}$. Colonies were suspended in prereduced brucella broth to a concentration equivalent to a McFarland 1.0 for anaerobic bacteria while aerobic bacteria and streptococci were suspended in sterile saline to a concentration equivalent to a McFarland 0.5. After inoculation of the respective agar plates with the bacterial inocula, $6 \mathrm{~mm}$ filter disks, impregnated with $20 \mu \mathrm{L}$ of the tested drugs at concentrations of $\times 10$ and $\times 100$ Cmax for DMARDs and $\times 1$ and $\times 10$ Cmax for antibiotic controls were placed on the surface (online supplemental table S1). Inhibitory zones were measured after an anaerobic incubation of 48-72 hour, $\mathrm{CO}_{2}$ enriched incubation of 24-48 hours and aerobic incubation of 24 hours at $36^{\circ} \mathrm{C}-37^{\circ} \mathrm{C}$, depending on the respective organism. Anaerobic and $\mathrm{CO}_{2}$-enriched environmental conditions were generated using AnaeroGen or $\mathrm{CO}_{2} \mathrm{Gen}$ sachets in combination with an anaerobic jar (all Thermo Fisher ScientificOxoid, Austria).

\section{Determination of minimum inhibitory concentrations}

Bacterial inocula were prepared as described for the agar diffusion assay, except of the bacterial concentrations of anaerobic bacteria which were prepared at a McFarland turbidity of 0.5 for these experiments. As previously described, a serial tube dilution assay was used for minimum inhibitory concentrations (MIC) determination of anaerobic bacteria. ${ }^{16}$ For testing of aerobic bacteria and streptococci a microdilution assay in 96-well u-bottom microtiterplates with a total volume of $200 \mu \mathrm{L}$ cation-adjusted Mueller-Hinton broth 
Table 1 Antimicrobial activity of aurothiomalate, methotrexate and sulfasalazine against RA associated pathogens

\begin{tabular}{|c|c|c|c|}
\hline & ATM & MTX & ssz \\
\hline Cmax & $1.4-4 \mu \mathrm{g} / \mathrm{mL}^{1723}$ & $0.2-0.6 \mu \mathrm{g} / \mathrm{mL}^{24}$ & $6.0 \mu \mathrm{g} / \mathrm{mL}\left(^{*}\right)$ \\
\hline \multicolumn{4}{|l|}{ Anaerobic bacteria } \\
\hline Actinomyces spp $(\mathrm{n}=6)$ & $>280 \mu \mathrm{g} / \mathrm{mL}(70 ;>280)$ & n.a. & $>600 \mu \mathrm{g} / \mathrm{mL}(300 ;>600)$ \\
\hline Capnocytophaga spp $(\mathrm{n}=6)$ & 35 g/mL (18; >280) & n.a. & $>600 \mu \mathrm{g} / \mathrm{mL}(600 ;>600)$ \\
\hline Eikenella spp $(\mathrm{n}=6)$ & $>280 \mu \mathrm{g} / \mathrm{mL}(18 ;>280)$ & n.a. & $>600 \mu \mathrm{g} / \mathrm{mL}(300 ;>600)$ \\
\hline Fusobacterium spp $(\mathrm{n}=6)$ & $53 \mu \mathrm{g} / \mathrm{mL}(18 ; 280)$ & $30 \mu \mathrm{g} / \mathrm{mL}(3.75 ;>30)$ & 300 ㅆg/mL (150; 300) \\
\hline Parvimonas spp $(n=6)$ & $210 \mu \mathrm{g} / \mathrm{mL}(70 ;>280)$ & n.a. & n.a. \\
\hline Prevotella spp $(\mathrm{n}=6)$ & $>280 \mu \mathrm{g} / \mathrm{mL}(>280 ;>280)$ & n.a. & n.a. \\
\hline Porphyromonas spp $(n=6)$ & $53 \mu \mathrm{g} / \mathrm{mL}(17.5 ; 140)$ & n.a. & $450 \mu \mathrm{g} / \mathrm{mL}(150 ;>600)$ \\
\hline \multicolumn{4}{|l|}{ Viridans Streptococci } \\
\hline Streptococcus spp $(n=8)$ & $>280 \mu \mathrm{g} / \mathrm{mL}(>280 ;>280)$ & $2.3 \mu \mathrm{g} / \mathrm{mL}(0.5 ; 15)$ & n.a. \\
\hline \multicolumn{4}{|l|}{ Aerobic bacteria } \\
\hline Escherichia coli $(n=6)$ & $>280$ ㅆg/mL (140; >280) & n.a. & n.a. \\
\hline Proteus mirabilis $(\mathrm{n}=6)$ & $>280 \mu \mathrm{g} / \mathrm{mL}(>280 ;>280)$ & n.a. & n.a. \\
\hline Staphylococcus aureus $(n=6)$ & $>280 \mu \mathrm{g} / \mathrm{mL}(>280 ;>280)$ & n.a. & n.a. \\
\hline
\end{tabular}

Minimum inhibitory concentrations, presented as median (min; $\max ) \mu \mathrm{g} / \mathrm{mL}$ for disease-modifying anti rheumatic drugs which demonstrated antimicrobial activity in the diffusion disk screening assay.

Cmax, maximum serum concentrations from diverse pharmacokinetic studies, as shown in online supplemental table 1; n.a., not applicable because no antimicrobial activity was observed in the agar diffusion screening assay; For the calculation of median minimum inhibitory concentrations, the highest concentrations tested were used if no inhibition was observed. *Pharmacokinetic data were taken from the summary of product characteristics (Sulfasalazin-Heyl, Germany). ATM, Aurothiomalate; MTX, Methotrexate; RA, rheumatoid arthritis; SSZ, Sulfasalazine.

(CA-MHB) or CA-MHB supplemented with $5 \%$ lysed horse blood and $20 \mathrm{mg} / \mathrm{L} \beta$-nicotinamide adenine dinucleotide were used, respectively. MICs were read after an incubation period of 18-24 hours for aerobic bacteria and streptococci as well as after 48-72 hours for anaerobic bacteria.

\section{RESULTS}

The agar diffusion screening assay revealed an antimicrobial activity of ATM against at least one isolate of all bacterial species tested. MTX demonstrated activity against $F$. nucleatum and Viridans streptococci whereas SSZ was active against Actinomyces spp, Capnocytophaga spp, E. corrodens, F. nucleatum and P. gingivalis. No other DMARD demonstrated antibacterial activity, whereas the antimicrobial controls penicillin-G and cefuroxime revealed high activity against all respective bacterial isolates tested.

MICs of ATM, MTX and SSZ are presented in table 1, online supplemental figure S1 and online supplemental table S2. Highest activity was observed for MTX against certain species of $V$. streptococci which were inhibited at concentrations $\geq 0.5 \mu \mathrm{g} / \mathrm{mL}$. ATM showed highest activity against Capnocytophaga spp, E. corrodens, F. nucleatum and $P$. gingivalis, with MICs of $>18 \mathrm{mg} / \mathrm{L}$. All other substances revealed antimicrobial concentrations far above their maximum serum concentrations (data not shown).

\section{DISCUSSION}

In this study, ATM, MTX and SSZ demonstrated antimicrobial activity against a wide range of bacterial species associated with the pathogenesis of RA or frequently found in the oral microbiome of patients with the disease. MTX demonstrated relevant activity against $V$. streptococci, considering doses up to 20-30 mg/week. ATM also showed potentially relevant activity against some isolates of Capnocytophaga spp, E. corrodens, F. nucleatum and $P$. gingivalis but to a lesser extent than MTX against streptococci and only when considering concentrations achieved after parenteral administration of high doses in the range of $50 \mathrm{mg} .{ }^{17}$ In contrast to that, antimicrobially active concentrations of SSZ and the other DMARDs tested, are not reached systemically in sera of patients with RA receiving conventional doses (online supplemental table S1).

As recently shown by Nayak et al MTX, like its antimicrobial counterpart trimethoprim, acts by inhibiting the bacterial dihydrofolate reductase (DHFR), resulting in reduced purine, pyrimidine and amino acid biosynthesis and thus inhibition of replication. ${ }^{18}$ Considering possible resistance mechanisms to trimethoprim, conclusions can probably be drawn about the cause of the strongly species-dependent antimicrobial activity of MTX due to the similar mechanism of action. These comprise impaired permeability, intrinsic or acquired insensitive DHFR, compensatory increased production of target enzymes or the expression of efflux pumps. ${ }^{18} 19$ 
It must be emphasised that some of the drugs used in the present study have multiple metabolites that may even possess increased antimicrobial activity. ${ }^{12}$ Therefore, their potential influence on the microbiome and thus their potential role in the treatment of RA might be underestimated given the limited antimicrobial activity observed in the present study. Sulfapyridine has a close relationship with sulfonamide antibiotics and thus an expectation of one of the highest antimicrobial activity among all DMARDs. Nevertheless, some studies have shown only low activity against group-A streptococci and pneumococci. ${ }^{71}$ In addition, a study examining the antimicrobial activity of gold compounds against Lactobacillus spp and Neisseria gonorrhoeae and a study investigating the activity of sulfapyridine against Mycobacterium avium subspecies showed a highly variable antimicrobial activity. ${ }^{10} 13$

Given the highly species-dependent antimicrobial activity observed in the present study, DMARDs might indirectly influence RA-initiating and/or RA-exacerbating pathogens through changes in the community composition of the human microflora. In addition to changes in the microbiome due to the direct antimicrobial activity of DMARDs, anti-inflammatory activity could also contribute via a variety of changes in the gut bacterial nutritional milieu and the resulting competition between beneficial and harmful pathogens. ${ }^{20}$ As demonstrated by using a gnotobiotic mouse model, MTX-induced shifts in the gut microbiome, which primarily included decreased abundances of Bacteroidetes members, led to decreased activation of the host immune system and thus reduced inflammation. ${ }^{18}$ This is consistent with previous data in patients with active RA showing enrichment of proinflammatory pathogens such as Prevotella copri and reduced abundances of bacteria such as Bacteroides spp, Blautia spp and Lachnospiraceae clades possessing antiinflammatory properties including the induction of regulatory $\mathrm{T}$ cells. ${ }^{21}$ This has also been supported by several studies among patients with RA showing an association between treatment efficacy of DMARDs and changes in the composition or partial restoration of the gut microbiome ${ }^{6815}$ Interestingly, a recent study found evidence that, particularly in patients with RA, the vast majority of oral microbes are transmissible to and subsequently colonise the colon. ${ }^{22}$ This suggests even further reaching implications of changes in the composition of the oral microflora induced by antimicrobially active DMARDs. Although the aforementioned mechanisms could contribute to the effect of DMARDs in the treatment of RA, no corresponding conclusions can be drawn based on the in vitro design of the present study.

In summary, ATM, MTX and SSZ demonstrated antimicrobial activity against a broad spectrum of RA-associated bacterial species but mostly at supratherapeutic systemic concentrations, although a potential biologically relevant effect through target site/organ enrichment must be considered. In this context, our results encourage future investigation of target site pharmacokinetics as well as circumstantial mechanisms such as interactions of DMARDs with the host mucosal immune system and the specific influences of DMARDs on the human microflora over time in form of longitudinal case-control studies.

Contributors MK, SW and DA conceived this study and participated in its design and coordination. MK, MO and KS designed the various experiments including agar diffusion screening assay, tube dilution and broth microdilution. MK drafted the manuscript and SW and DA participated in the data analysis and revision of the manuscript. All authors read and approved the final manuscript.

Funding The authors have not declared a specific grant for this research from any funding agency in the public, commercial or not-for-profit sectors.

Competing interests None declared.

Patient consent for publication Not applicable.

Ethics approval The study was approved by the local ethics committee of the Medical University of Vienna, Austria (EK no. 1324/2013).

Provenance and peer review Not commissioned; externally peer reviewed.

Open access This is an open access article distributed in accordance with the Creative Commons Attribution Non Commercial (CC BY-NC 4.0) license, which permits others to distribute, remix, adapt, build upon this work non-commercially, and license their derivative works on different terms, provided the original work is properly cited, appropriate credit is given, any changes made indicated, and the use is non-commercial. See: http://creativecommons.org/licenses/by-nc/4.0/.

ORCID iDs

Manuel Kussmann http://orcid.org/0000-0002-8149-6655

Daniel Aletaha http://orcid.org/0000-0003-2108-0030

\section{REFERENCES}

1 Evans-Marin H, Rogier R, Koralov SB, et al. Microbiota-dependent involvement of Th17 cells in murine models of inflammatory arthritis. Arthritis Rheumatol 2018;70:1971-83.

2 Li S, Yu Y, Yue Y, et al. Microbial infection and rheumatoid arthritis. $J$ Clin Cell Immunol 2013;4.

3 Pretorius E, Akeredolu O-O, Soma P, et al. Major involvement of bacterial components in rheumatoid arthritis and its accompanying oxidative stress, systemic inflammation and hypercoagulability. Exp Biol Med 2017;242:355-73.

4 Maresz KJ, Hellvard A, Sroka A, et al. Porphyromonas gingivalis facilitates the development and progression of destructive arthritis through its unique bacterial peptidylarginine deiminase (pad). PLOS Pathog 2013;9:e1003627.

5 Martinez-Martinez RE, Abud-Mendoza C, Patiño-Marin N, et al. Detection of periodontal bacterial DNA in serum and synovial fluid in refractory rheumatoid arthritis patients. $J$ Clin Periodontol 2009;36:1004-10.

6 Zhang X, Zhang D, Jia H, et al. The oral and gut microbiomes are perturbed in rheumatoid arthritis and partly normalized after treatment. Nat Med 2015;21:895-905.

7 White HJ. The relationship between temperature and the Streptococcidal activity of sulfanilamide and sulfapyridine in vitro. $J$ Bacteriol 1939;38:549-62.

8 Bodkhe R, Balakrishnan B, Taneja V. The role of microbiome in rheumatoid arthritis treatment. Ther Adv Musculoskelet Dis 2019;11:1759720X1984463.

9 Beyer K, Zaura E, Brandt BW, et al. Subgingival microbiome of rheumatoid arthritis patients in relation to their disease status and periodontal health. PLoS One 2018;13:e0202278.

10 Greenstein RJ, Su L, Shahidi A, et al. On the action of 5-aminosalicylic acid and sulfapyridine on $\mathrm{M}$. avium including subspecies paratuberculosis. PLoS One 2007;2:e516.

11 Lowell FC, Spring WC, Finland M. Bactericidal action of sodium sulfapyridine and of a GLUCOSE-SULFAPYRIDINE solution in human blood. J Clin Invest 1940;19:215-8.

12 Sayers E, MacGregor A, Carding SR. Drug-microbiota interactions and treatment response: relevance to rheumatoid arthritis. AIMS Microbiol 2018;4:642-54.

13 Elkashif A, Seleem MN. Investigation of auranofin and goldcontaining analogues antibacterial activity against multidrugresistant Neisseria gonorrhoeae. Sci Rep 2020;10:5602.

14 Maier L, Pruteanu M, Kuhn M, et al. Extensive impact of nonantibiotic drugs on human gut bacteria. Nature 2018;555:623-8. 
15 Lorenzo D, GianVincenzo Z, Carlo Luca R, et al. Oral-Gut microbiota and arthritis: is there an evidence-based axis? J Clin Med 2019;8. doi:10.3390/jcm8101753. [Epub ahead of print: 22 Oct 2019].

16 Emani S, Gunjiganur GV, Mehta DS. Determination of the antibacterial activity of simvastatin against periodontal pathogens, Porphyromonas gingivalis and Aggregatibacter actinomycetemcomitans: an in vitro study. Contemp Clin Dent 2014;5:377-82.

17 Rubinstein HM, Dietz AA. Serum gold. II. levels in rheumatoid arthritis. Ann Rheum Dis 1973;32:128-32.

18 Nayak RR, Alexander M, Deshpande I, et al. Methotrexate impacts conserved pathways in diverse human gut bacteria leading to decreased host immune activation. Cell Host Microbe 2021;29:377. e11:362-77.

19 Bergmann R, van der Linden M, Chhatwal GS, et al. Factors that cause trimethoprim resistance in Streptococcus pyogenes. Antimicrob Agents Chemother 2014;58:2281-8.
20 Bäumler AJ, Sperandio V. Interactions between the microbiota and pathogenic bacteria in the gut. Nature 2016;535:85-93.

21 Scher JU, Sczesnak A, Longman RS, et al. Expansion of intestinal Prevotella copri correlates with enhanced susceptibility to arthritis. Elife 2013;2:e01202.

22 Schmidt TS, Hayward MR, Coelho LP, et al. Extensive transmission of microbes along the gastrointestinal tract. Elife 2019;8. doi:10.7554/eLife.42693. [Epub ahead of print: 12 Feb 2019].

23 Capparelli EV, Bricker-Ford R, Rogers MJ, et al. Phase I clinical tria results of auranofin, a novel antiparasitic agent. Antimicrob Agents Chemother 2017;61. doi:10.1128/AAC.01947-16. [Epub ahead of print: 27 Dec 2016].

24 Liu Y, Zhou S, Nissel J, et al. The pharmacokinetic effect of coadministration of apremilast and methotrexate in individuals with rheumatoid arthritis and psoriatic arthritis. Clin Pharmacol Drug Dev 2014;3:456-65. 